\title{
PENDETEKSI KEBOCORAN TABUNG LPG MELALUI SMS GATEWAY MENGGUNAKAN SENSOR MQ-6 BERBASIS ARDUINO PADA PT BANGUN INTI GEMILANG
}

\author{
Moch. Ibnu Safari \\ Listina Nadhia Ningsih \\ Muhammad Husni Farid \\ Email : ibnu.safari@raharja.info, listina.nadhia@raharja.info, husni@raharja.info
}

\begin{abstract}
The increasing level of population, making the level of consumption on natural resources is also increasing. In the case of this increase occurred in the use of fuels LPG (Liquefied Petroleum Gas). With the LPG fuel is increasing, allowing the occurrence of fires caused by leakage of LPG gas. However, not all providers of LPG gas cylinders provide additional safety systems on LPG they sell. So it takes a LPG gas leak detectors and systems that can perform countermeasures in case of leakage of LPG cylinders. For that made the tool pendekteksi leakage of LPG gas by using a system of notification SMS by using SIM900a, Sensor MQ-6 that can detect gas LPG and DC motor to drive the exhaust to neutralize the air when leakage of LPG gas, so as to provide a warning if the owner of LPG cylinders being are outside the house. All the components are controlled using Arduino Uno. This tool has the advantage of being easy to use and compatible with all communication devices based on SMS. And this tool can be developed using the Internet-based notfikasi.
\end{abstract}

Keyword : LPG, Motor DC, SMS, Arduino Uno

\begin{abstract}
ABSTRAK
Semakin bertambahnya tingkat populasi masyarakat, membuat tingkat konsumsi masyarakat pada sumber daya alam juga meningkat. Dalam hal ini peningkatan terjadi pada penggunaan bahan bakar LPG (Liquefied Petroleum Gas), . Dengan pengguna bahan bakar LPG yang semakin meningkat, sehingga memungkinkan terjadinya kebakaran yang disebabkan oleh kebocoran gas LPG. Namun tidak semua penyedia tabung gas LPG memberikan sistem keselamatan tambahan pada tabung LPG yang mereka jual. Sehingga dibutuhkan alat pendeteksi kebocoran gas LPG dan sistem yang dapat melakukan penanggulangan jika terjadi kebocoran tabung LPG. Untuk itulah dibuat alat pendekteksi kebocoran gas LPG dengan menggunakan sistem notifikasi SMS dengan menggunakan SIM900a, Sensor MQ-6 yang dapat mendeteksi gas LPG dan motor DC untuk menggerakkan exhaust untuk menetralisir udara saat terjadi kebocoran gas LPG, sehingga dapat memberikan peringatan jika pemilik tabung LPG sedang berada diluar rumah. Seluruh komponen tersebut dikontrol dengan menggunakan Arduino uno. Alat ini memiliki keunggulan karena mudah digunakan dan kompatibel dengan seluruh perangkat komunikasi yang berbasis SMS. Dan alat ini dapat dikembangkan lagi menggunakan notfikasi berbasis internet.
\end{abstract}

Kata Kunci : LPG, Sensor MQ-6, SIM900a, Motor DC, SMS, Arduino Uno 


\section{PENDAHULUAN}

Perkembangan ilmu pengetahuan dan teknologi yang cukup pesat berdampak pada meningkatnya kebutuhan manusia akan sumber daya energi. Dimana selama ini lebih banyak menggunakan sumber energi yang dihasilkan oleh alam sebagai sumber energi utama. Melalui sumber energi inilah manusia menggunakannya untuk keperluan sehari-hari, termasuk penggunaan LPG (Liquefied Petroleum Gas). LPG merupakan campuran dua gas yang tidak beracun yang mudah terbakar, yang dikenal sebagai propana $\left(\mathrm{C}_{3} \mathrm{H}_{8}\right)$ dan butana $\left(\mathrm{C}_{4} \mathrm{H}_{10}\right)$. Propilena dan butylenes juga tercampur didalamnya tapi dalam jumlah yang kecil.

Selain digunakan untuk keperluan bahan bakar didapur, LPG juga bisa digunakan sebagai bahan bakar kendaraan bermotor atau yang biasa disebut BBG (Bahan Bakar Gas). Gas LPG yang dapat terbakar secara sempurna, membuat LPG juga menjadi pilihan yang bagus bagi kendaraan. Karena dapat membuat kendaraan dapat bekerja secara maksimal.

Namun dari banyak kelebihan yang bisa didapatkan dari pemanfaatan LPG, ada juga beberapa faktor berbahaya yang perlu diperhatikan. Seperti proses pemasangan tabung LPG yang tidak benar dapat menyebabkan terjadinya kebocoran gas yang nantinya dapat memicu ledakan. Untuk itulah diperlukan alat yang dapat mendeteksi kebocoran gas dan memberikan notifikasi jika terjadi kebocoran gas, sehingga bisa segera melakukan penanggulangan dini untuk mencegah dampak negatif dari kebocoran gas LPG.

Pada PT Bangun Inti Gemilang yang merupakan salah satu perusahaan jasa konstruksi. Banyak rumah atau pun ruko (rumah toko) yang sudah mereka bangun tidak dilengkapi dengan sistem pemantauan kebocoran gas LPG. Padahal jika terjadi kebocoran gas hal ini akan sangat berbahaya karena dapat menyulut terjadinya kebakaran.

Dalam penelitian ini, peneliti menggunakan sensor MQ-6 berbasis pada mikrokontroller Arduino untuk mendeteksi kobocoran gas pada tabung LPG. MQ-6 memiliki keakuratan dalam mendeteksi kebocoran gas LPG, iso-butane, propane, \& LNG. MQ-6 memiliki ketahanan terhadap asap rokok, alkohol dan asap yang dihasilkan dari proses memasak. Sehingga keakuratan dalam mendeteksi gas lebih tinggi, karena sensor MQ-6 lebih sensitif terhadap gas-gas yang mudah terbakar seperti LPG, iso-butane, propane dan LNG.

Alat ini juga dilengkapi dengan exhaust dan sensor api. Exhaust yang akan berfungsi sebagai sistem penanggulangan dini kebocoran gas LPG dan sensor api yang berfungsi sebagai sistem alarm jika gas sudah menyulut terjadinya api. Sehingga dapat menekan dampak buruk yang ditimbulkan.

Alat ini juga akan langsung memberikan notifikasi melalui SMS dan buzzer jika terjadi kebocoran pada tabung LPG dan atau terdeteksi adanya api. Buzzer yang akan memberikan peringatan pada penghuni rumah yang berada didalam, sedangkan SMS sebagai media notifikasi jika pemilik rumah tidak ada dirumah. Sehingga kondisi tabung LPG dapat selalu dipantau kapanpun dan dimanapun. 


\section{LITERATURE RIVIEW}

1. Penelitian yang dilakukan oleh Asep Saefullah, Hadi Syahrial, Ari Santoso (2012), Jurusan Sistem Mahasiswa Pasca Sarjana, Universitas Budi Luhur Komputer, Jurusan sistem Komputer STMIK Raharja, Pasca Sarjana Ilmu Komputer Universitas Budi Luhur, yang berjudul "Pendeteksi Kebocoran Tabung Gas LPG menggunakan Mikrokontroller AT89S2051 Melalui Handphone Sebagai Media Informasi" Penelitian menjelaskan kebakaran sering terdengar sebagai akibat tabung gas elpiji meledak, penyebab meledaknya tabung gas ini karena kebocoran pada selang, tabung atau pada regulatornya yang tidak terpasang dengan baik. Pada saat terjadi kebocoran akan tercium gas yang menyengat, gas inilah yang nantinya akan meledak apabila ada sulutan atau percikan listrik, atau rokok. Pada intinya ledakan dapat dihindarkan apabila terdapat penanganan dini saat gas keluar atau pada saat kebocoran gas terjadi. Pada penelitian ini dibuat sebuah program untuk mendeteksi kebocoran Gas dengan memanfaatkansensor gas TGS-2610. Pada saat sensor mendeteksi adanya bau gas maka sistem mengaktifkan buzzer sebagai simulasi penanganan dini. Selain itu, sistem ini juga dihubungkan dengan handphone, untuk memberi informasi bahwa kondisi gastelah berbahaya kepada pihak terkait. Hasilnya berupa sebuah alat yang mampu mengirim informasi berupa SMS ke pihak terkait, membunyikan buzzer sebagai peringatan dini ketika ruang terakumulasi gas yang berbahaya dan mematikannya jika kondisi ruang sudah aman dari gas.

2. Penelitian yang telah dilakukan oleh Tias Harfiansyah Akbar [2010] dari Fakultas Ilmu Komputer dan Teknologi Informasi, Universitas Gunadarma dalam bentuk jurnal dengan judul " Pendeteksi Kebocoran Tabung Gas Dengan Menggunakan Sensor Gas Figarro TGS 2610 Berbasis Mikrokontroler AT89S52". Pada Jurnal ini penulis menggunakan sensor gas Figarro TGS 2610 menggunakan mikrokontroller AT89S52 dengan media LCD sebagai outputnya.

3. Penelitian yang telah dilakukan oleh Fahad Albahri [2013] dari STMIK Raharja sebagai bentuk Tugas Akhir dengan judul "Pendeteksi Asap Rokok Untuk Lingkungan Bebas Asap Rokok Berbasis Mikrokontroler Atmega32u4”. Pada Tugas Akhir ini penulis menggunakan sensor Mq-2, Atmega32u4, kamera, \& LCD 16x2. Prinsip dari kerja sistem yang akan di rancang adalah sensor asap menjadi media inputan pada mikrokontroller ATmega32u4, dan aplikasi untuk menampilkan video dari webcam ataupun mengontrol pergerakan kamera menggunakan visual basic.net.

Dari tiga Literature Review yang ada, telah banyak penelitian mengenai pemantauan menggunakan sensor gas. Di samping itu juga ada pembahasan mengenai perancangan alat pendeteksi kebocoran gas menggunakan sensor Figarro TGS 2610 dan sistem pendeteksi kebocoran menggunakan SMS berbasis mikrokontroller AT89S2051. Maka dari itu penulis mengambil satu sample atau contoh untuk dijadikan acuan dari ke 3 (tiga) literature review diatas yaitu dengan judul Pendeteksi Kebocoran Tabung Gas LPG menggunakan Mikrokontroller AT89S2051 Melalui Handphone Sebagai Media Informasi yang menggunakan jenis penelitian dan pengembangan. Pada penelitian tersebut peneliti belum menggunakan atau memanfaatkan Arduino sebagai media pemrosesan dan sensor MQ-6 sebagai media input. 


\section{LANDASAN TEORI}

\section{Arduino Uno}

Arduino Uno memiliki 14 pin input/output yang mana 6 pin dapat digunakan sebagai output PWM, 6 analog input, crystal osilator $16 \mathrm{MHz}$, koneksi USB, jack power, kepala ICSP, dan tombol reset. Arduino Uno mampu men-support mikrokontroller; dapat dikoneksikan dengan komputer menggunakan kabel USB.

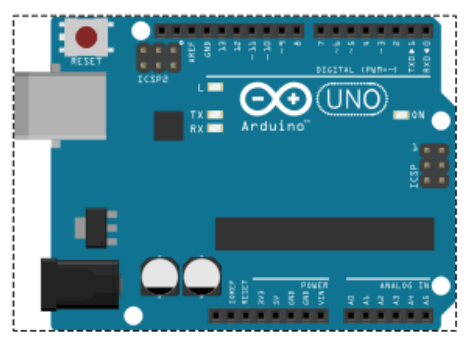

Gambar 1. Mikrokontroller Arduino Uno

Seperti yang tertera pada situs resmi Arduino, yaitu www.arduino.co.cc. Arduino Uno dapat diberikan power melalui koneksi USB atau power supply. Powernya menyala secara otomatis. Power supply dapat menggunakan adaptor DC atau baterai. Adaptor dapat dikoneksikan dengan mencolok jack adaptor pada koneksi port input supply. Board arduino dapat dioperasikan menggunakan supply dari luar sebesar 6 - 20 volt. Jika supply kurang dari $7 \mathrm{~V}$, kadangkala pin $5 \mathrm{~V}$ akan menyuplai kurang dari 5 volt dan board bisa menjadi tidak stabil. Jika menggunakan lebih dari $12 \mathrm{~V}$, tegangan di regulator bisa menjadi sangat panas dan menyebabkan kerusakan pada board. Rekomendasi tegangan ada pada 7 sampai 12 volt. Arduino sendiri memiliki IDE untuk compiler. Proses kerja Arduino Uno ialah melakukan pemrograman pada IDE, compile, dan upload binary/hex file ke kontroler. Berbeda dengan processing yang kode hasil compile langsung dijalankan di komputer, kode hasil compile Arduino harus diupload ke kontroler sehingga dapat dijalankan.

\section{Sensor MQ-6}

Sensor ini biasa digunakan untuk alat pendeteksi kebocoran gas di lingkungan rumah tangga atau industri, sangat cocok untuk mendeteksi LPG, iso-butane, propane, \& LNG. Dapat menghindari gangguan dari alkohol, asap masakan dan asap rokok. 


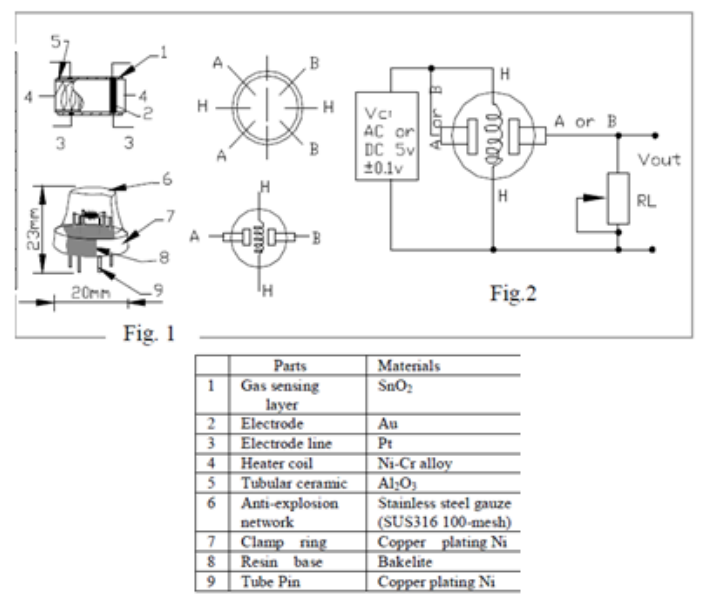

Gambar 2. Datasheet MQ-6

(Sumber : Datasheet MQ-6)

\section{Modul Sensor Api}

Modul ini sangat sensitive terhadap api dan radiasi. Modul ini juga bisa mendeteksi sumber cahaya normal dengan cakupan radius sekitar 760nm-1100nm. Jarak deteksi bisa mencapai $100 \mathrm{~cm}$.

Modul sensor api bisa mengeluarkan output analog ataupun digital. Bisa digunakan sebagai alarm kebakaran atau robot pendeteksi api.

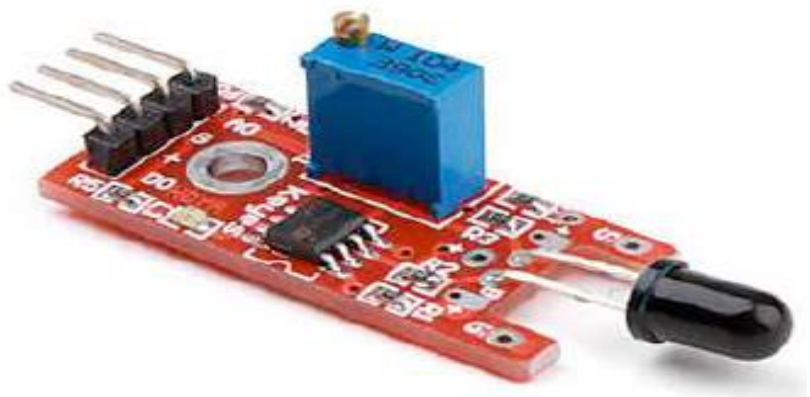

Gambar 3. Modul Sensor Api

(Sumber : Datasheet Flame Sensor Module)

\section{Modul GSM SIM900A}

Modul GSM SIM900A untuk arduino bisa digunakan untukmengirim menerima pesan dan membuat / menerima panggilan seperti ponsel biasa dengan menggunakan kartu SIM dari sebuah provider jaringan seluler. Dengan cara menghubungkan modul GSM dengan papan arduino dan masukkan kartu SIM dari operator yang menyediakan cakupan GPRS.

Untuk bisa menghubungkan dengan jaringan seluler, shield membutuhkan kartu SIM yang dikeluarkan oleh provider jaringan seluler. 


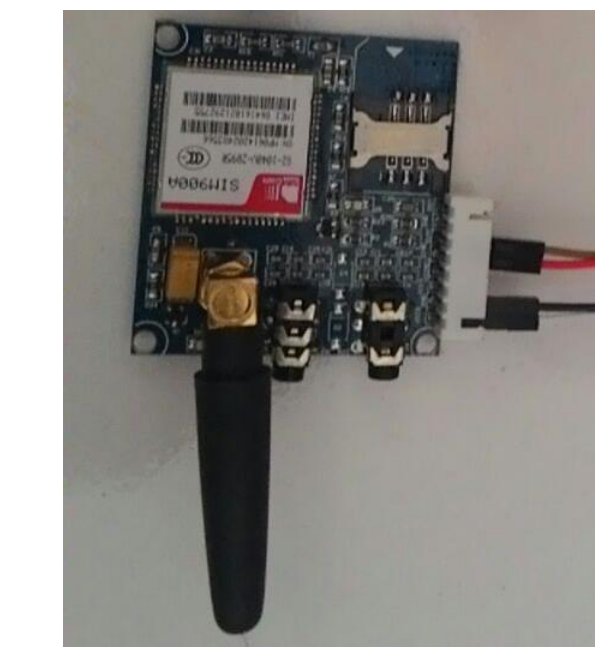

Gambar 4. Modul GSM SIM900A

(Sumber : Datasheet Modul GSM SIM900A)

\section{Listing Program}

Perancangan perangkat lunak, adalah melakukan penulisan listing program ke dalam suatu Software Arduino 1.5.8 dengan menggunakan bahasa pemrograman C, dimana perintah-perintah program tersebut akan di eksekusi oleh hardware atau sistem yang di buat. Berikut ini adalah gambar dari listing program alat.

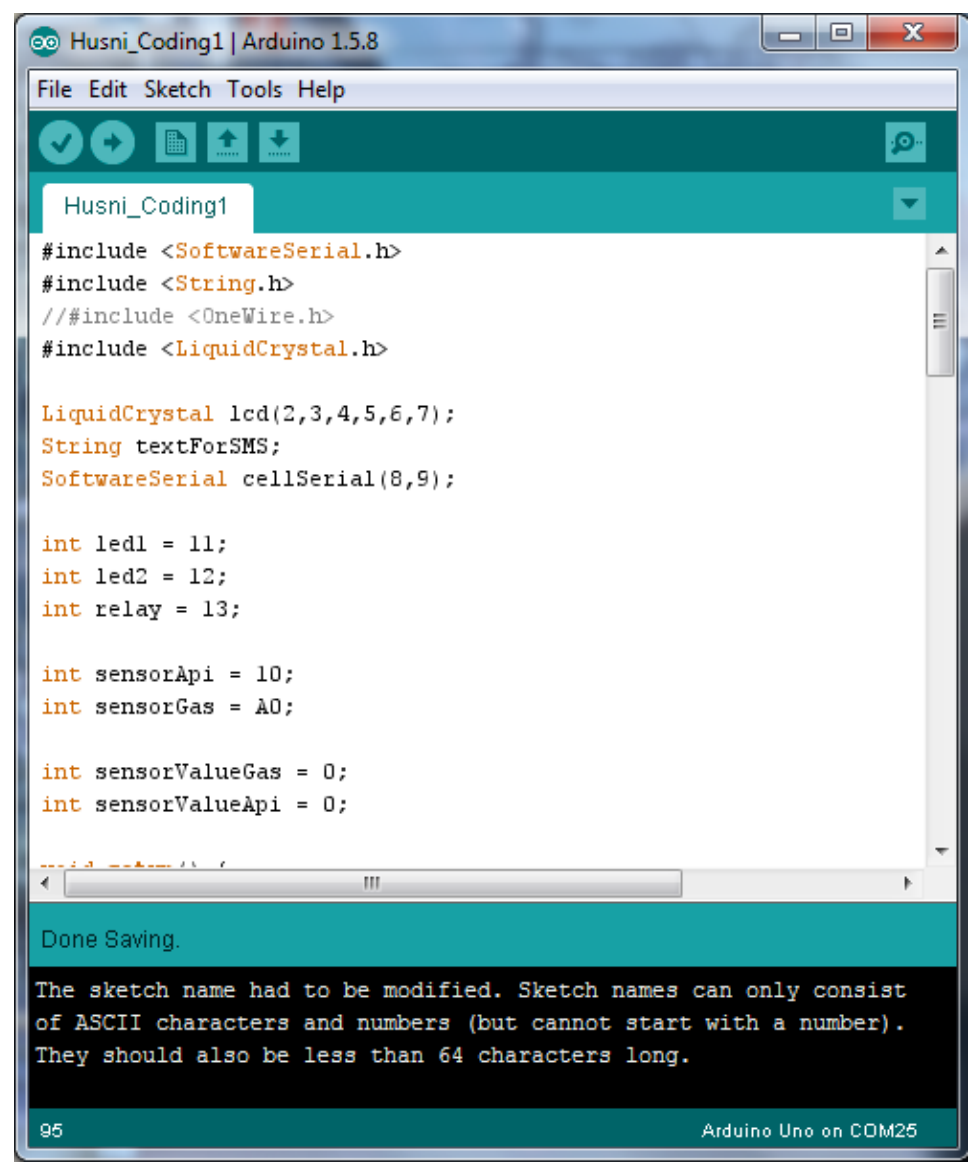

Gambar 5. Listing Program 


\section{PERMASALAHAN}

Gas LPG adalah salah satu sumber daya energi yang banyak digunakan oleh masyarakat, hal ini terjadi semenjak pemerintah melakukannya konversi energi dari minyak tanah ke LPG. Sehingga penggunaan LPG tidak hanya pada kalangan individu rumah tangga, tapi juga digunakan untuk industri bisnis. LPG juga sudah mulai diterapkan untuk keperluan angkutan umum. Namun dengan tingginya tingkat penggunaan LPG ini, tidak disertai dengan sistem pengaman yang mumpuni. LPG hanya dilengkapi dengan campuran gas ethanethiol yang memiliki aroma menyengat, untuk membantu orang dalam mendeteksi kebocoran pada gas LPG. Namun beberapa orang baru mengetahui jika gas yang bocor sudah memenuhi ruangan atau menimbulkan bau yang sangat menyengat. Hal ini lah yang dapat memicu terjadinya kebakaran.

Sebagai contoh jika saat terjadi kebocoran gas LPG dan pemiliknya sedang tidak berada dirumah, maka gas yang bocor akan terus keluar hingga memenuhi ruangan. Tentu saja pemiliknya tidak akan mengetahui hal ini sampai dia pulang ke rumah. Dan ini akan sangat berbahaya jika ada percikan api yang bisa ditimbulkan melalui konsleting listrik atau hal-hal lainnya.

Pendeteksi kobocoran gas ini menggunakan sensor MQ-6 yang dilengkapi dengan exhaust dan sensor api sebagai antisipasi. Sensor MQ-6 berfungsi sebagai pendeteksi gas LPG, dimana sensor ini sangat peka dengan gas LPG, iso-butane, propane dan LNG. Sehingga sensor ini memiliki keakuratan yang tinggi dalam mendeteksi gas LPG. Sensor MQ-6 juga memiliki ketahanan terhadap asap rokok, alkohol dan asap yang dihasilkan dalam proses memasak.

Bagaimana cara membuat Arduino agar dapat mendeteksi kobocoran tabung LPG ? Arduino yang dihubungkan dengan sensor MQ-6 untuk medeteksi kobocoran pada tabung LPG, sehingga ditemukan sebuah solusi yang terbaik bahwa sensor MQ-6 tersebut memiliki tingkat pendeteksian yang tinggi dan akurat. Bagaimana membuat Arduino agar dapat berkomunikasi dengan perangkat SMS gateway ? Arduino dikonfigurasikan dengan modul GSM SIM900A supaya bisa terhubung dengan SMS gateway supaya dapat mengirimkan notifikasi mengenai kondisi tabung LPG. Bagaimana membuat Arduino agar dapat memberikan informasi melalui SMS ? Menyisipkan perintah AT command pada program supaya Arduino dapat mengirimkan SMS notifikasi ke nomor yang telah ditentukan.

\section{PEMBAHASAN}

\section{Diagram Blok}

Rancangan blok diagram dari Pendeteksi Kebocoran Tabung LPG Melalui SMS Gateway Menggunakan Sensor MQ-6 Berbasis Arduino, menggunakan beberapa komponen utama seperti sensor gas MQ-6, sensor api dan modul GSM SIM900A. Untuk komponen pendukung menggunakan komponen, yaitu buzzer dan LCD 16x2. Secara lengkap dapat dilihat pada gambar 5 berikut ini : 


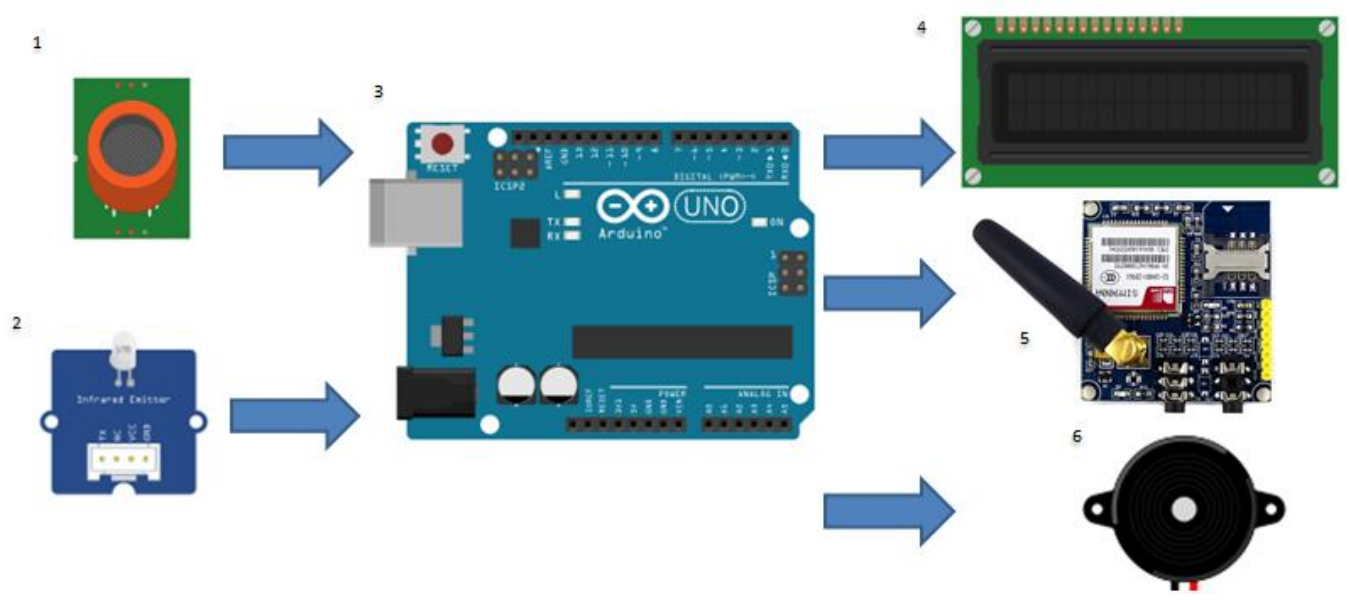

Gambar 5. Diagram Blok Rangakaian

Keterangan dari gambar diatas :

1. Sensor MQ- $6^{1}$ berfungsi untuk mendeteksi kebocoran gas pada tabung LPG, sedangkan flame sensor ${ }^{2}$ berfungsi mendeteksi api jika memang efek dari kebocoran gas memicu terjadinya kebakaran. Kemudian mengirimkannya ke arduino untuk diproses.

2. Arduino $^{3}$ memproses data dari kedua sensor, kemudian mengirimkannya pada perangkat output, yaitu $\mathrm{LCD}^{4} \&$ modul GSM SIM900A ${ }^{5}$.

3. Buzzer ${ }^{6}$ akan aktif jika salah satu sensor atau kedua sensor tersebut aktif.

4. Modul GSM SIM900A ${ }^{5}$ akan langsung mengirimkan pesan SMS ke nomor hp yang telah di input kedalam arduino.

5. $\mathrm{LCD}^{4}$ akan menampilkan pesan mengenai status sensor.

\section{PERANCANGAN PROTOTIPE}

Dari semua sensor sebelumnya, kemudian semuanya dirangkai hingga setiap sensor dapat berkomunikasi dengan arduino dan prototipe alat ini dapat berjalan. Berikut adalah tata letak kompenen alat pendeteksi kebocoran gas LPG.

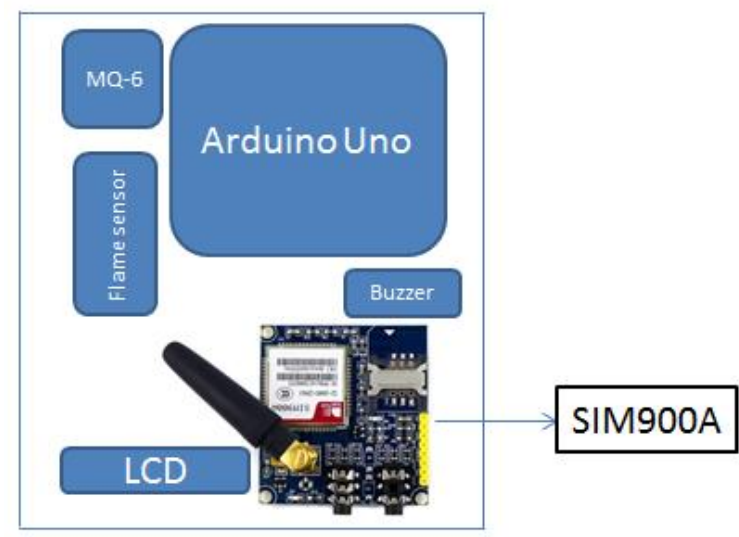

Gambar 6. Prototipe Alat

\section{CARA KERJA ALAT}

Cara kerja alat ini adalah :

1. Saat alat dinyalakan seluruh komponen aktif dan sensor langsung mulai bekerja. 
2. Masing - masing sensor, yaitu MQ-6 dan sensor api akan langsung bereaksi jika terdeteksi gas LPG dan/atau api.

3. Saat gas LPG dan/atau api terdeteksi oleh sensor MQ-6 dan sensor api, maka Arduino akan memproses data tersebut. Dan mengirim pesan SMS melalui SIM900a dan mengaktfikan buzzer

4. Selanjutnya LCD akan menampilkan pesan mengenai status sensor.

\section{UJI COBA IMPLEMENTASI}

Pada uji coba implementasi ini dilakukan percobaan untuk mendeteksi jangkauan jarak sensor MQ-6, uji coba ini dilakukan pada ruangan dengan sirkulasi udara yang normal dan sensitifitas MQ-6 yang di atur pada tingkat normal dengan mengunakan gas LPG. Sensor api diatur dengan sensitifitas yang normal dan lilin sebagai sumber apinya. Untuk SMS menggunakan operator GSM Indosat sebagai pengirim dan operator yang digunakan sebagai penerima adalah operator GSM XL. Hasil nya dapat di lihat pada tabel 1 berikut ini.

\begin{tabular}{|c|c|c|c|c|c|c|}
\hline \multirow{2}{*}{$\begin{array}{c}\text { Jarak } \\
(\mathrm{cm})\end{array}$} & \multicolumn{3}{|c|}{ Nilai Gas LPG } & \multirow{2}{*}{$\begin{array}{c}\text { Waktu } \\
\text { Netral } \\
(\mathrm{s})\end{array}$} & $\begin{array}{c}\text { Sensor } \\
\text { Api }\end{array}$ & SMS (s) \\
\cline { 2 - 4 } & $5(\mathrm{~s})$ & $10(\mathrm{~s})$ & $15(\mathrm{~s})$ & 5,41 & On & 1,25 \\
\hline $0-2$ & 442 & 393 & 382 & 8,53 & On & 1,30 \\
\hline $0-4$ & 401 & 340 & 363 & 7,59 & On & 1,20 \\
\hline $0-8$ & 372 & 362 & 171 & 30,48 & Off & 1,33 \\
\hline $0-16$ & 279 & 249 & 252 & & \\
\hline
\end{tabular}

Tabel 1. Uji coba implementasi

Keterangan :

Jarak $(\mathrm{cm})$

Nilai Gas LPG

: Jarak sensor dengan sumber gas LPG dan Api.

Waktu Netral(s)

Sensor Api

SMS(s)

: Nilai kepekatan gas pada jeda waktu tertentu.

: Waktu yang dibutuhkan sensor untuk kembali pada kondisi normal.

: Pada jarak berapa sensor api akan aktif.

: Waktu yang dibutuh untuk pegiriman SMS notifikasi.

\section{KESIMPULAN}

Dari perancangan dan uji coba implementasi yang dilakukan maka diperoleh kesimpulan yaitu, Alat ini secara normal mendeteksi nilai gas pada kisaran 100-150, dan setelah uji coba yang dilakukan alat ini secara maksimal dapat digunakan pada jarak $0-8 \mathrm{~cm}$. Karena pada jarak tersebut sensor gas MQ-6 dan sensor api masih bisa mendeteksi gas dan api secara akurat. Dengan rata-rata waktu pengiriman pesan yaitu 1,27 detik pada semua jarak uji coba sensor, maka pesan notifikasi dapat diterima secara cepat. Sehingga dari percobaan implementasi tersebut dapat di tarik kesimpulan bahwa alat ini dapat berfungsi secara efektif.

\section{DAFTAR PUSTAKA}

Adelia, dan Jimmy Setiawan. 2011. "Implementasi Customer Relationship Management (CRM) pada Sistem Reservasi Hotel berbasisi Website dan Desktop". Bandung: Universitas Kristen Maranatha. Vol. 6, No. 2, September 2011:113-126. 
Archarya,Shivani. Pandya, Vidhi. 2013. "Bridge between Black Box and White Box - Gray Box Testing Technique" Internasional Journal of Electronics and Computer Science Engineering ISSN- 2277-1956 Volume 2 No.1

Ari Beni Santoso,Martinus dan Sugiyanto.2013."Pembuatan Otomasi Pengaturan Kereta Api, Pengereman, Dan Palang Pintu Pada Rel Kereta Api Mainan Berbasis Mikrokontroler".Jurnal Fema,Vol.1,No.1

Baharodi, Alireza. 2014. "Natural Gas Processing : Technology and Engineering Design". USA: Elsevier Inc

Darmawan. Deni. 2013. “Sistem Informasi Manajemen". PT Remaja Rosdakarya Offset : Bandung.

Hartono. Bambang. 2013. "Sistem Informasi Manajemen Berbasis Komputer". PT Asdi Mahasatya : Jakarta.

Khanna, Ika Nur. 2013. "WirelessMon, Very Handle to Capturing your WiFi Network Access". Diambil dari http://ilmukomputer.org

Komputer, Wahana. 2014. "Mudah Membuat Aplikasi SMS Gateway dengan CodeIgniter". Jakarta : PT Elex Media Komputindo.

Malik, Ibnu dan Mohammad Unggul Juwana. 2010. "ANEKA PROYEK Mikrokontroler PIC16F84/A". Jakarta: PT Elex Media Komputindo.

Nikolaos Bourbakis, Konstantina S. Nikita and Ming Yang. 2013. "International Journal of Monitoring and Surveillance Technology Resarch". Vol 1:2, ISSN:2166-7241, EISSN:2166-725X. IGI PA, USA.

Rizky. 2011. “Konsep Dasar Rekayasa Perangkat Lunak”. Jakarta: PT Prestasi Pustakaraya

Sastra Hadiprawira,Arie.2014."Pembangunan Aplikasi Game Cerita Rakyat Fabel'.Skripsi.Fakultas Teknik dan Ilmu Komputer,Universitas Komputer Indonesia.Bandung.

Shivani Acharya dan Vidhi Pandya Lecturer. "Bridge between Black Box and White BoxGray Box Testing Technique" International Journal of Electronics and Computer Science Engineering.ISSN- 2277-1956 Vol.2

Simarmata, Janner. 2010. “Rekayasa Perangkat Lunak”. Yogyakarta: CV Andi Offset.

Sriwijaya, M.Si, Dedi Karsadi dan Drs.Dadang Subagja.2011. "Solusi Cerdas Servis Ponsel".Jakarta Selatan:PT Kawan Pustaka

Sulindawati, dan Muhammad Fathoni. 2010. "Pengantar Analisa Perancangan Sistem". Medan: STMIK Triguna Dharma. Vol. 9, No. 2, Agustus 2010.

Sutabri, Tata. 2012. “Analisis Sistem Informasi”. Andi Offset : Yogyakarta. 
Syahwil,Muhammad.2013."Panduan Mudah Simulasi \& Praktek Mikrokontroler Arduino".Yogyakarta:ANDI

Taufiq. Rohmat. 2013. "Sistem Informasi Manajemen”. Graha Ilmu : Yogyakarta. 